\title{
Ion Exchange Equilibrium between DOWEX 1X8 Resin Modified by Polyethyleneimine and Electrolyte Solutions
}

\author{
Chiraz Hannachi, Fatma Guesmi, Khaoula Missaoui, Hana Tounakti, Béchir Hamrouni \\ UR Traitement et Dessalement des Eaux, Faculté des Sciences de Tunis, Université de Tunis El Manar, Manar II, Tunisie \\ Email: chiraz_hannach@yahoo.fr
}

Received April 25, 2013; revised May 28, 2013; accepted June 25, 2013

Copyright (C) 2013 Chiraz Hannachi et al. This is an open access article distributed under the Creative Commons Attribution License, which permits unrestricted use, distribution, and reproduction in any medium, provided the original work is properly cited.

\begin{abstract}
In order to improve the selectivity of anion exchange resin, the surface of gel type anion exchange resin was modified with polyethyleneimine (PEI). In the proposed work an attempt to the utilization of commercial anion exchange resin modified by adsorption of polyethyleneimine was investigated. Many conditions of modification of anion exchange resin surface were studied. The influent parameters on the DOWEX 1X8 resin modification were determined using a factorial experimental design. The ion exchange reactions were studied for modified and unmodified resin and electrolyte solutions containing $\mathrm{Cl}^{-}, \mathrm{NO}_{3}^{-}$and $\mathrm{SO}_{4}^{2-}$. All experiments were performed at constant ionic strength $\mathrm{I}=0.3$ $\mathrm{mol} \cdot \mathrm{L}^{-1}$ and constant temperature $\mathrm{T}=298 \mathrm{~K}$. Ionic exchange isotherms were established for the binary systems: $\mathrm{Cl}^{-} / \mathrm{NO}_{3}^{-}, \mathrm{Cl}^{-} / \mathrm{SO}_{4}^{2-}$ and $\mathrm{NO}_{3}^{-} / \mathrm{SO}_{4}^{2-}$. The obtained results show that nitrate ion was more sorbed than chloride and sulfate. The order of preference for the anions studied in this investigation is: $\mathrm{NO}_{3}^{-}>\mathrm{Cl}^{-}>\mathrm{SO}_{4}^{2-}$. All the results given by this resin were compared with those obtained with the AMX anion exchange membrane. Selectivity coefficients and thermodynamic constants for the three binary systems and for the two resins were determined. The modified resin became more selective towards monovalent anions.
\end{abstract}

Keywords: Resin; Modification; Polyethyleneimine; Factorial Design; Binary System Isotherm; Selectivity Coefficient

\section{Introduction}

Ion exchange resins and membranes are widely used in various fields such as electrodialytic concentration of seawater to produce sodium chloride and demineralization of saline water. Many studies were carried out, in the last years, on the modification of ion exchange resins and membranes [1-16].

Matsusaki et al. [17] tried to modify the surface of geltype anion exchange resin by adsorption of anionic polyelectrolyte in order to change the ion exchange selectivity of this resin, especially to make the ion exchange of divalent anions more difficult. They showed that the ion exchange capacity of the modified resin was decreased and the rate of ion exchange reaction became slow. Berbar et al. [18] used anion exchange resin Amberlite IRA 900 modified with polyethyleneimine to separate nitrate and chloride ions. They found that the modified resin became more selective toward nitrate when the modification was attempted at $\mathrm{pH}=9.8$ during 3 days.

Moreover, Amara and Kerdjoudj [19,20] conducted several studies on the modification of ion exchange resins by adsorption of polyethyleneimine in order to separate and recover metal ions from industrial effluents.

Takata et al. [8] studied the modification of transport properties of ion exchange membranes in order to prepare an excellent monovalent cation permselective membrane. They observed that after the adsorption of the polyelectrolyte in membrane surface, the ion exchange capacity decreased and the electrical resistance increased.

In order to improve the ion exchange membrane selectivity, Guesmi et al. [21] modified the AMX anion exchange membrane by adsorption of polyethyleneimine. Obtained results showed that for the modified membrane the selectivity towards sulfate ion decreased and the modified membrane became more selective towards monovalent anions.

In this work the examination of adsorption of polyethyleneimine (PEI) on the anion exchange resin is attempted. An experimental design methodology using two-level full factorial design was used to investigate the 
influence of the principal experimental parameters (initial concentration of PEI, molecular weight of the PEI and the $\mathrm{pH}$ of the solution) on the modification of the DOWEX 1X8 resin and then to determine the optimal modification conditions.

Therefore, the present investigation attempts were made to study the influence of the adsorption layer of PEI on the DOWEX 1X8 resin surface on the ion exchange with the binary systems $\left(\mathrm{Cl}^{-} / \mathrm{NO}_{3}^{-}\right)$, $\left(\mathrm{Cl}^{-} / \mathrm{SO}_{4}^{2-}\right)$ and $\left(\mathrm{NO}_{3}^{-} / \mathrm{SO}_{4}^{2-}\right)$. The affinity order and the values of selectivity coefficients and thermodynamic constants will be determined both for the modified and unmodified resin. All experiments were carried out at constant ionic strength of $0.3 \mathrm{~mol} \cdot \mathrm{L}^{-1}$ and at $298 \mathrm{~K}$.

Ions analyses were performed by ionic chromatography, coupled to a conductimetric detector.

\section{Materials and Methods}

\subsection{Reagents}

All experiments were used with a gel-type anion exchange resin DOWEX 1X8 in a chloride form. Polyethyleneimine are used to from modification layer on the surface of the anion exchange resin. All other reagents used were from Sigma Aldrich.

Polyethyleneimine (PEI) is a polymeric amine having chelating properties with various metal ions. It existed as a linear or branched structure. It has also good solubility in water and suitable molecular weight [16]. The principal characteristics of PEI used in this study are given in Table 1.

\subsection{Analytical Method}

The amount of polyethyleneimine (PEI) in the solution was measured using the UV absorption spectrum of the copper-PEI complex. To do this, the solution containing PEI was mixed with a cupric sulfate solution. The maximum absorption of the copper-PEI complex was located at $326 \mathrm{~nm}$ [21].

The concentrations of different anions in the solution were determined by ion chromatography using a Metrohm 761 compact IC with conductivity detector and chemical suppression, $4.6 \times 250 \mathrm{~mm}$ Metrosep A Supp 1 (6.1005.300), an eluent of $3 \mathrm{mmol} \cdot \mathrm{L}^{-1}$ sodium carbonate at $1 \mathrm{~mL} \cdot \mathrm{min}^{-1}$, an injection volume of $20 \mu \mathrm{L}$, and a pressure from 8 to $9 \mathrm{MPa}$.

Table 1. Principal characteristics of polyethyleneimine.

\begin{tabular}{cc}
\hline Molecular weight & 1300 \\
\hline Specific viscosity & $200-500(\mathrm{cP})$ \\
Density & 1.08 \\
\hline
\end{tabular}

\subsection{Modification of DOWEX 1X8 Anion Exchange Resin}

The anion exchange resin was pretreated with a sodium solution; the pretreated resin was thoroughly washed with water. The surface of DOWEX 1X8 was modified by adsorption of the PEI. Resin was immersed in a stirred PEI aqueous solution of the given concentration for 8 days.

The influent parameters such as concentration, molecular weight and $\mathrm{pH}$ of the solution; on the DOWEX $1 \mathrm{X} 8$ resin modification were determined using a factorial experimental design.

\subsection{Ion Exchange Equilibrium between DOWEX $1 X 8$ Resin and Electrolyte Solutions}

When equilibrium is reached, the various ions present in solution are measured by ion chromatography, and concentrations of the various species present in the resin are determined from load balance and mass balance relations:

Load balance in the:

$$
\begin{aligned}
& \operatorname{Resin}(r): C_{E}=[i]_{r}+[j]_{r} \\
& \text { solution }(s): C_{0}=[i]_{s}+[j]_{S}
\end{aligned}
$$

Mass balance in the:

$$
\begin{array}{r}
\operatorname{resin}(r): m_{s} \cdot C_{E}+V \cdot[i]_{0}=V \cdot[i]_{s}+m_{s} \cdot[i]_{r} \\
\text { solution }(s): V \cdot[j]_{0}=V \cdot[j]_{s}+m_{s} \cdot[j]_{r}
\end{array}
$$

We also define the equivalent mole fractions of $i$, $X_{s}(i)$ and $X_{r}(i)$ respectively in the solution and in the resin by:

$$
X_{s}(i)=\frac{z_{i} \cdot[i]_{s}}{C_{0}} \text { and } X_{r}(i)=\frac{z_{i} \cdot[i]_{r}}{C_{E}}
$$

where, $\mathrm{z}_{\mathrm{i}}$ is the charge of ion $i$.

$[i]_{S}$ is the concentration of the ionic species in solution, $[i]_{r}$ is the solute concentration in the resin, $C_{E}$ is the ion exchange capacity of the resin and $V$ and $\mathrm{m}$ are the volume of the solution and the mass of the dry ion exchange resin, respectively.

\section{Results and Discussions}

\subsection{Effect of the Experimental Parameters on the Modification of DOWEX 1X8 Resin}

The objective of this study is to determine the optimal conditions for modification of the DOWEX 1X8 anion exchange resin. The modification of ion exchange resin by adsorption of a polyelectrolyte and in particular by simple immersion of the resin in a solution of polyelec- 
trolyte led us to choose three factors, namely, the initial concentration of polyethyleneimine (X1), the molecular weight of the polyethyleneimine (X2) and the $\mathrm{pH}$ of the medium (X3) [22].

We studied in this part the influence of these factors on the modification of the anionic resin DOWEX 1 X8. We adopted the methodology of experimental research plans through full factorial. Indeed, full factorial designs at two levels (minimum $(-1)$ and maximum $(+1)$ ) are the most simple, they are also the most useful because they form the basis of all early study. Level $(-1)$ reflects the lowest value that can take the value of the factor studied and the level (1) reflects the higher value of the factor. These plans are used to calculate the average effect, the main effects of factors and their interactions $2-2,3-3$, etc., until the general interaction between $\mathrm{k}$ factors.

To reflect the variation of the experimental responses studied in a factorial design $2^{\mathrm{k}}$ (three variables), we use the following mathematical model:

$$
\begin{aligned}
Y= & b_{0}+b_{1} X_{1}+b_{2} X_{2}+b_{3} X_{3} \\
& +b_{1} b_{2} X_{1} X_{2}+b_{1} b_{3} X_{1} X_{3}+b_{2} b_{3} X_{2} X_{3} \\
& +b_{1} b_{2} b_{3} X_{1} X_{2} X_{3}
\end{aligned}
$$

where, $Y$ experimental response, $X_{i}$ coded variable ( -1 or $+1), b_{i}$ estimation of the principal effect of the factor $i$ for the response $Y$ and $b_{i j}$ estimation of interaction effect between factor $\mathrm{i}$ and $\mathrm{j}$ for the response $Y$.

The coefficients of the equation model were calculated in the experimental field listed in Table 2. The experimental design and results are given in Table 3. According to the results obtained, the coefficients of the polynomial model were calculated using the Nemrod-W Software:

$$
\begin{aligned}
Y= & 1.319+0.811 X_{1}-0.06 X_{2} \\
& -0.655 X_{3}-0.064 X_{1} X_{2}-0.321 X_{1} X_{3} \\
& +0.043 X_{2} X_{3}+0.038 X_{1} X_{2} X_{3}
\end{aligned}
$$

The effects and interactions of the various investigated factors are represented in Figure 1.

The graphical analysis of this figure shows that the initial concentration of polyethyleneimine is very influential in changing the DOWEX 1X8, its effect is positive. An increase in concentration results in an increase of the amount adsorbed polyethyleneimine. The $\mathrm{pH}$ of the medium is the second important factor in the modification of the resin studied. Its effect is negative.

Thus, the increase in $\mathrm{pH}$ decreases the amount of adsorbed polyethyleneimine. The molecular weight PEI has a negligible effect on the change.

There is also an interaction between PEI concentrations (X1) and the $\mathrm{pH}(\mathrm{X} 3)$ of the solution. Thus, the effect of $\mathrm{pH}$ depends on the chosen concentration of PEI
Table 2. Experimental region investigated for the modification of the DOWEX 1 X8 resin.

\begin{tabular}{ccccc}
\hline \multirow{2}{*}{$\begin{array}{c}\text { Coded } \\
\text { variables }\left(\boldsymbol{X}_{\boldsymbol{i}}\right)\end{array}$} & $\begin{array}{c}\text { Factors } \\
\left(\mathbf{U}_{\mathbf{i}}\right)\end{array}$ & Unit & \multicolumn{2}{c}{\begin{tabular}{c} 
Experimental field \\
\cline { 4 - 5 }
\end{tabular}} \\
\hline$X_{1}$ & {$[\mathrm{PEI}]$} & $\mathrm{g} \cdot \mathrm{L}^{-1}$ & 0.5 & 1.5 \\
$X_{2}$ & $\begin{array}{c}\mathrm{M}_{\mathrm{w}} \\
(\mathrm{PEI})\end{array}$ & $\mathrm{g} \cdot \mathrm{mol}^{-1}$ & 1300 & $10^{6}$ \\
$X_{3}$ & $\mathrm{pH}$ & - & 8.8 & 10.8 \\
\hline
\end{tabular}

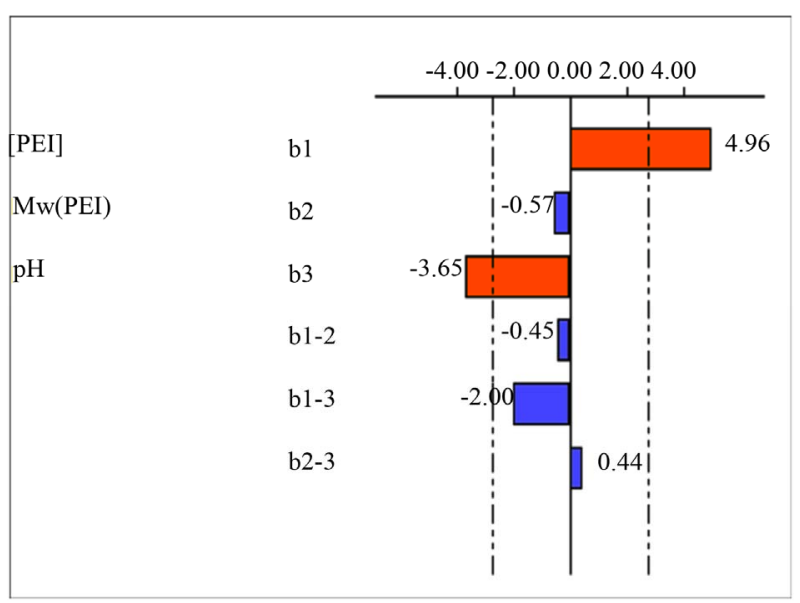

Figure 1. Graphical analysis of the effect of concentration of PEI, molecular weight of the PEI and the $\mathrm{pH}$ of the solution on modification of the DOWEX 1 X8 resin.

in the experimental field and vice versa. This interaction has a negative effect on the response studied.

According to these results we note that the concentration of PEI and the $\mathrm{pH}$ of the solution are the most affected factors on the modification of the resin. In order to better interpret these results, we used Pareto analysis [23] to calculate the percentage effect of each factor on the response, according to the following equation:

$$
P_{i}=\frac{b_{i}^{2}}{\sum b_{i}^{2}} \times 100(i \neq 0)
$$

where $b_{i}$ represents the estimation of the principal effect of the factor $i$ for the response. The Pareto graphic analysis is presented in Figure 2. The graphical analysis of this figure shows that the concentration of polyethyleneimine and the $\mathrm{pH}$ of the solution are the most important fac tors on the adsorption of PEI on the surface of the resin DOWEX 1X8, their effect is $88.93 \%$ of the studied response. In addition, the interaction between these two factors is the most important

The graphical analysis of this figure shows that the concentration of polyethyleneimine and the $\mathrm{pH}$ of the solution are the most important factors on the adsorption of PEI on the surface of the resin DOWEX 1X8, their effect is $88.93 \%$ of the studied response. In addition, the 
Table 3. Factorial experimental design, experimental plan and results.

\begin{tabular}{|c|c|c|c|c|c|c|c|}
\hline \multirow{2}{*}{ Experiment number } & \multicolumn{3}{|c|}{ Experimental design } & \multicolumn{3}{|c|}{ Experimental plan } & \multirow{2}{*}{$Q_{\text {ads }}($ PEI $)\left(\mathbf{m g} \cdot \mathbf{c m}^{-2}\right)$} \\
\hline & $\mathrm{X}_{1}$ & $\mathrm{X}_{2}$ & $\mathrm{X}_{3}$ & $\mathrm{U}_{1}$ & $\mathrm{U}_{2}$ & $\mathrm{U}_{3}$ & \\
\hline 1 & -1 & -1 & -1 & 0.5 & 1300 & 8.8 & 4.75 \\
\hline 2 & +1 & -1 & -1 & 1.5 & 1300 & 8.8 & 20.00 \\
\hline 3 & -1 & +1 & -1 & 0.5 & $10^{6}$ & 8.8 & 4.05 \\
\hline 4 & +1 & +1 & -1 & 1.5 & $10^{6}$ & 8.8 & 16.66 \\
\hline 5 & -1 & -1 & +1 & 0.5 & 1300 & 10.8 & 1.00 \\
\hline 6 & +1 & -1 & +1 & 1.5 & 1300 & 10.8 & 7.40 \\
\hline 7 & -1 & +1 & +1 & 0.5 & $10^{6}$ & 10.8 & 1.20 \\
\hline 8 & +1 & +1 & +1 & 1.5 & $10^{6}$ & 10.8 & 6.66 \\
\hline
\end{tabular}

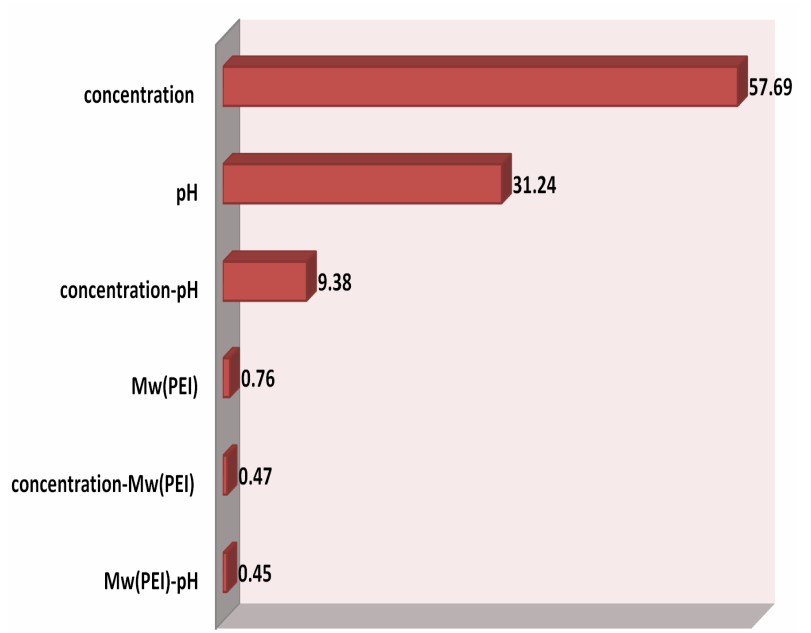

Figure 2. Graphical pareto analysis.

interaction between these two factors is the most important. These two factors and their interaction bring about $98.31 \%$ of the response. However, the molecular weight of PEI and other interactions have a negligible effect; they represent only $1.7 \%$ of the studied response.

In the light of these results, the initial concentration of this polyelectrolyte and the $\mathrm{pH}$ of the solution were fixed respectively at the highest value $\left(1.5 \mathrm{~g} \cdot \mathrm{L}^{-1}\right)$ and the lowest value $(\mathrm{pH}=8.8)$, in order to increase the adsorption amount of PEI in the surface of resin. These results were also reported by different authors [16,21] where they found that the modification of anion exchange membrane is more effective with a high concentration and a low $\mathrm{pH}$.

\subsection{Characteristics of the Modified and the Unmodified DOWEX 1X8 Resins}

Humidity percentage and ion exchange capacity values for the modified and the unmodified DOWEX 1 X8 resins were determined and presented in Table 4.
Table 4. Humidity percentage and ion exchange capacity values for the modified and the unmodified DOWEX 1X8 resins.

\begin{tabular}{ccc}
\hline & Unmodified resin & Modified resin \\
\hline $\begin{array}{c}\text { Humidity percentage (\%) } \\
\begin{array}{c}\text { Ion exchange } \\
\text { capacity }\left(\mathrm{meq} \cdot \mathrm{g}^{-1}\right)\end{array}\end{array}$ & 38 & 35 \\
\hline
\end{tabular}

Obtained results show that the ion exchange capacities of the modified and unmodified resins did not vary significantly ranging from 2.84 to $2.27 \mathrm{meq} \cdot \mathrm{g}^{-1}$ of dried resin in the chloride form. Ion exchange capacity decreases by $20 \%$ after modification, which indicates the presence of electrostatic interactions between PEI and the functional groups of the resin.

\subsection{Effect of Modification on Ion Exchange Equilibrium}

Competitive ion exchange reactions were studied for the modified and the unmodified resins involving $\mathrm{Cl}^{-}, \mathrm{NO}_{3}^{-}$and $\mathrm{SO}_{4}^{2-}$ ions.

All experiments were carried out at constant ionic strength of $0.3 \mathrm{~mol} \cdot \mathrm{L}^{-1}$ and at $298 \mathrm{~K}$. The isotherms of binary ion exchange were established for the couples $\left(\mathrm{Cl}^{-} / \mathrm{NO}_{3}^{-}\right),\left(\mathrm{Cl}^{-} / \mathrm{SO}_{4}^{2-}\right)$ and $\left(\mathrm{NO}_{3}^{-} / \mathrm{SO}_{4}^{2-}\right)$ and are given in Figure 3.

\subsection{Affinity Order}

These isotherms make possible the determination of the affinity order of the unmodified and modified resins. The obtained results show that nitrate ion was the most sorbed than chloride and sulfate.

The order of preference for the anions studied in this investigation is: $\mathrm{NO}_{3}^{-}>\mathrm{Cl}^{-}>\mathrm{SO}_{4}^{2-}$.

In addition, it can be shown that for the modified DOWEX 1 X8 resin, the sulfate anion affinity decrease 


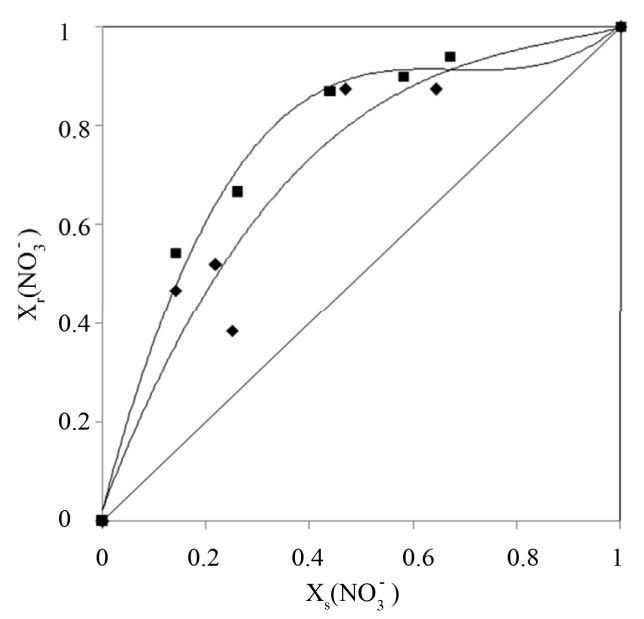

(a)

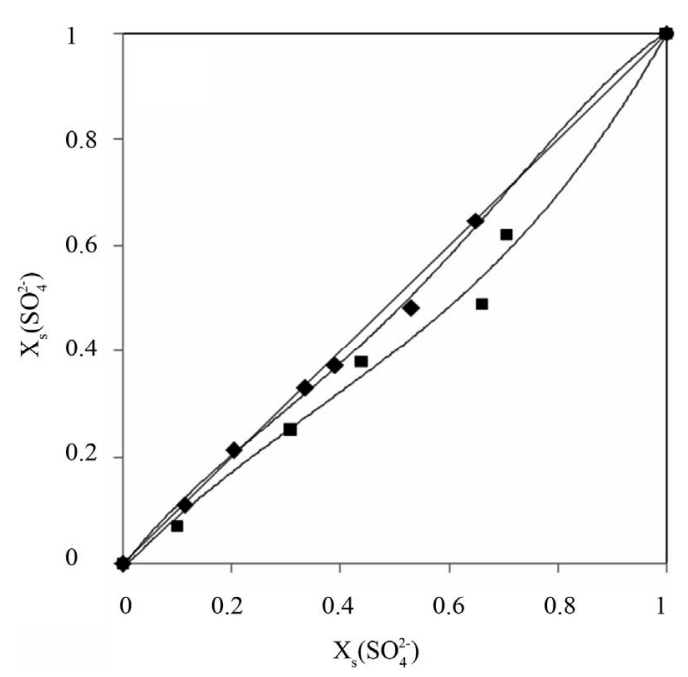

(b)

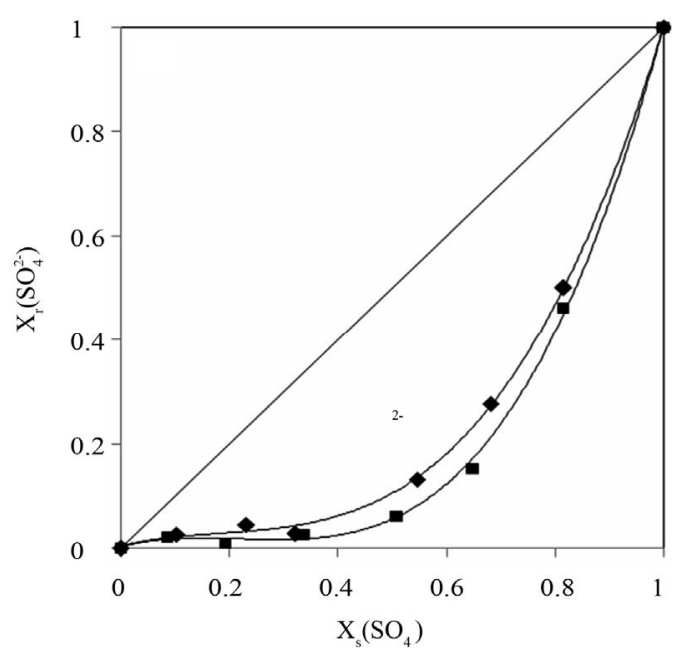

(c)

Figure 3. Ion exchange isoterms, resin $/ \operatorname{systems}\left(\mathrm{Cl}^{-} / \mathrm{NO}_{3}^{-}\right)$
(a), $\left(\mathrm{Cl}^{-} / \mathrm{SO}_{4}^{2-}\right)$
(b) and $\left(\mathrm{NO}_{3}^{-} / \mathrm{SO}_{4}^{2-}\right)$
(c), $\mathrm{I}=0.3 \mathrm{~mol} \cdot \mathrm{L}^{-1}$

and $\mathrm{T}=\mathbf{2 9 8} \mathrm{K}$. compared with the chloride and nitrate anions. Guesmi et al. [24] studied the ion exchange equilibrium between the AMX membrane and the same binary systems at a total concentration of $0.3 \mathrm{~mol} \cdot \mathrm{L}^{-1}$. They found that the modified membrane became more selective for the monovalent anions than the bivalent anions. Amara and Kerdjoudj $[19,20]$ conducted several studies on the modification of ion exchange resins by adsorption of polyethyleneimine in order to separate and recover metal ions from industrial effluents, they found that after the modification, ion exchange resins became more selective for the monovalent ions.

\subsection{Selectivity Coefficients and Thermodynamics Constant}

According to the ion exchange reaction given by Equation (9):

$$
z_{b} A_{r}^{z_{a^{-}}}+z_{a} B_{s}^{z_{b^{-}}} \leftrightarrows z_{b} A_{s}^{z_{a}-}+z_{a} B_{r}^{z_{b}-}
$$

The thermodynamic equilibrium constant is related to the selectivity coefficient by the following equation:

$$
K_{A}^{B}=K_{A}^{B} \times\left(\frac{\gamma_{r}(B)}{\gamma_{s}(B)}\right)^{z_{a}} \times\left(\frac{\gamma_{s}(A)}{\gamma_{r}(A)}\right)^{z_{b}}
$$

where $\gamma_{s}(i)$ and $\gamma_{r}(i)$ are the activity coefficients of ion $i$ in the solution and in the resin, respectively.

The activity coefficients in the solution were determined according to the extended Debye-Hückel model as given in Equation (11):

$$
\log \gamma_{s}(i)=\frac{-A z_{i}^{2} \sqrt{I}}{1+B a_{i} \sqrt{I}}+b_{i} \cdot I
$$

where $A$ and $B$ are the Debye-Hückel constants, $I$ is the ionic strength for aqueous solution, $z_{i}$ the charge of the ionic species and $a_{i}$ is the hydrated ionic radius of ion $i$.

The activity coefficients in the resin phase (Equations (12) and (13)) were calculated using the Wilson equations [25]:

$$
\begin{aligned}
& \gamma_{r}(A)=\exp \left[\begin{array}{l}
1-\ln \left(X_{r}(A)+X_{r}(B) \cdot \Lambda_{A B}\right) \\
-\frac{X_{r}(A)}{X_{r}(A)+X_{r}(B) \cdot \Lambda_{A B}} \\
-\frac{X_{r}(B) \cdot \Lambda_{B A}}{X_{r}(B)+X_{r}(A) \cdot \Lambda_{B A}}
\end{array}\right] \\
& \gamma_{r}(B)=\exp \left[\begin{array}{l}
1-\ln \left(X_{r}(B)+X_{r}(A) \cdot \Lambda_{B A}\right) \\
-\frac{X_{r}(B)}{X_{r}(B)+X_{r}(A) \cdot \Lambda_{B A}} \\
-\frac{X_{r}(A) \cdot \Lambda_{A B}}{X_{r}(A)+X_{r}(B) \cdot \Lambda_{A B}}
\end{array}\right]
\end{aligned}
$$


where $\Lambda_{A B}$ and $\Lambda_{B A}$ are the Wilson binary interaction parameters

Selectivity coefficients will be given in our study from the quantity of counter-ions in the solution and the resin. Selectivity coefficients for the binary systems $\left(\mathrm{Cl}^{-} / \mathrm{NO}_{3}^{-}\right),\left(\mathrm{Cl}^{-} / \mathrm{SO}_{4}^{2-}\right)$ and $\left(\mathrm{NO}_{3}^{-} / \mathrm{SO}_{4}^{2-}\right)$ were calculated from experimentally measured concentrations as described below. Table 5 summarizes the selectivity coefficients and thermodynamics constant of these studied systems for the modified and unmodified resins.

The values obtained show that for the modified DOWEX $1 \mathrm{X} 8$ resin, the selectivity coefficients for the studied binary systems decrease compared with those corresponding to the unmodified DOWEX 1 X8 resin. These results show an improvement of the selectivity.

Thermodynamic equilibrium constants $\left(K_{A}^{B}\right)$ are greater than selectivity coefficients $\left(K_{A}^{B}\right)$ similarly for the modified resin and unmodified one. The influence of ionic strength is more important in ion exchange systems when bivalent ions are involved [26].

\section{Conclusion}

In order to determine the optimal experimental conditions for the modification of the DOWEX1X8 anionic resin, the experimental design methodology has been adopted in this study. Factorial design results show that the main influent parameters of the adsorption of PEI on the surface of the resin were the initial concentration and the $\mathrm{pH}$ of the solution.

Selectivity coefficients $K_{\mathrm{Cl}^{-}}^{\mathrm{NO}_{3}^{-}}, K_{2 \mathrm{Cl}^{-}}^{\mathrm{SO}_{4}^{2-}}$ and $K_{2 \mathrm{NO}_{3}^{-}}^{\mathrm{SO}_{4}^{2-}}$ were determined and decreased after modification. Thermodynamic constants were determined. These results show that the modification of the resin surface improves the selectivity towards monovalent anions.

Table 5. The selectivity coefficients and thermodynamics constant values for the modified and unmodified resin at $25^{\circ} \mathrm{C}$.

\begin{tabular}{lccc}
\hline & Systems A/B & $K_{A}^{B}$ & $K_{A}^{B}$ \\
\hline $\begin{array}{c}\text { DOWEX 1X8 } \\
\text { unmodified }\end{array}$ & $\left(\mathrm{Cl}^{-} / \mathrm{NO}_{3}^{-}\right)$ & 5.77 & 6.67 \\
& $\left(\mathrm{Cl}^{-} / \mathrm{SO}_{4}^{2-}\right)$ & 0.07 & 0.14 \\
& $\left(\mathrm{NO}_{3}^{-} / \mathrm{SO}_{4}^{2-}\right)$ & 0.009 & 0.006 \\
$\begin{array}{c}\left(\mathrm{Cl}^{-} / \mathrm{NO}_{3}^{-}\right) \\
\text {modified }\end{array}$ & $\left(\mathrm{Cl}^{-} / \mathrm{SO}_{4}^{2-}\right)$ & 0.71 & 9.75 \\
& $\left(\mathrm{NO}_{3}^{-} / \mathrm{SO}_{4}^{2-}\right)$ & 0.003 & 0.04 \\
\hline
\end{tabular}

\section{REFERENCES}

[1] Y. Mizutani, "Ion Exchange Membranes with Preferential Permselectivity for Monovalent Ions," Journal of Membrane Science, Vol. 54, No. 5, 1990, p. 233. http://dx.doi.org/10.1016/S0376-7388(00)80612-2

[2] V. Suendo, M. Minagawa and A. Tanioka, "Bipolar Interface Formation of Cationic Characteristics in Aqueous Electrolyte Solution," Langmuir, Vol. 18, 2002, pp. 62-66. http://dx.doi.org/10.1021/la011479r

[3] V. Suendo, R. Eto and A. Tanioka, "Ionic Rectification Properties of a Bipolar Interface Consisting of a Cationic Surfactant and Cation-Exchange Membrane," Journal of Colloid and Interface Science, Vol. 250, No. 2, 2002, pp. 507-509. http://dx.doi.org/10.1006/jcis.2002.8343

[4] T. Sata and R. Izuo, "Studies on Cation-Exchange Membranes Having Permselectivity between Cations in Electrodialysis," Colloid and Polymer Science, Vol. 256, No. 8, 1978, p. 757. http://dx.doi.org/10.1007/BF01438033

[5] A. Chapotot, V. Lopez, A. Lindheimer, N. Aouad and C. Gavach, "Mechanical Vapour Compression Desalination Plants-A Case Study," Desalination, Vol. 101, No. 2, 1995, p. 141. http://dx.doi.org/10.1016/0011-9164(95)00017-V

[6] T. Sata and Y. Mizutani, "Modification of Properties of Ion Exchange Membranes. VI. Electrodialytic Transport Properties of Cation Exchange Membranes with an Electrodeposition Layer of Cationic Polyelectrolytes," Journal of Polymer Science, Vol. 17, 1979, p. 1199.

[7] T. Sata, "Electrodialysis Method to Permeate Lower... Presence of Water-Soluble Polymers," Journal of Colloid and Interface Science, Vol. 44, No. 3, 1973, p. 393. http://dx.doi.org/10.1016/0021-9797(73)90315-9

[8] K. Takata, Y. Yamamoto and T. Sata, "Modification of Transport Properties of Charged Layer on the Membrane Surface by Sulfonyl-Amide Bonding," Bulletin of the Chemical Society of Japan, Vol. 69, No. 3, 1996, pp. 797-804. http://dx.doi.org/10.1246/bcsj.69.797

[9] T. Sata, Y. Ishil, K. Kawamura and K. Matsusaki, "Composite Membranes Prepared from Cation Exchange Membranes and Polyaniline and Their Transport Properties in Electrodialysis," Journal of the Electrochemical Society, Vol. 146, No. 2, 1999, pp. 585-591. http://dx.doi.org/10.1149/1.1391648

[10] T. Sata, S. Ogura and F. Kishimoto, "Properties of Composite Membranes from Ion Exchange Membranes and Conducting Polymers. Change in Acid Transport," Journal of Membrane Science, Vol. 84, No. 3, 1993, p. 259. http://dx.doi.org/10.1016/0376-7388(93)80021-O

[11] T. Sata, "Relation of Electrical Potential Generation to Preparation Conditions of Composite Membranes," Chemistry of Materials, Vol. 3, No. 5, 1991, p. 838. http://dx.doi.org/10.1021/cm00017a019

[12] T. Sata, T. Funakoshi and K. Akai, "Preparation and Transport Properties of Composite Membranes Composed of Cation Exchange Membranes and Polypyrrole," Macromolecules, Vol. 29, No. 11, 1996, pp. 4029-4035. http://dx.doi.org/10.1021/ma951543+ 
[13] T. Sata, "Studies on Ion-Exchange Membranes with Permselectivity for Specific Membranes and Polypyrrole," Macromolecules, Vol. 29, No. 11, 1996, pp. 4029-4035. http://dx.doi.org/10.1021/ma951543+

[14] T. Sata, "Preparation of Redox Cell Properties of Cation Exchange Membrane Combined Anisotropically with Polypyrrole," Journal of Membrane Science, Vol. 66, No. 23, 1992, pp. 289-294. http://dx.doi.org/10.1016/0376-7388(92)87018-S

[15] Y. Berbar, M. Amara and H. Kerdjoudj, “Anion Exchange Resin Applied to a Separation between Nitrate and Chloride Ions in the Presence of Aqueous Soluble Polyelectrolytes," Desalination, Vol. 223, No. 1-3, 2008, pp. 238-242. http://dx.doi.org/10.1016/j.desal.2007.01.218

[16] M. Amara and H. Kerdjoudj, "A Modified Anion Exchange Membrane Applied to Purification of Effluent Containing Different Anions. Pretreatment before Desalination," Desalination, Vol. 206, No. 1-3, 2007, pp. 205-209. http://dx.doi.org/10.1016/j.desal.2006.02.067

[17] K. Matsusaki, O. Hashimoton, O. Kuroki, T. Sata, "Selectivity of Anion Exchange Resin Modified with Anionic Polyelectrolyte," Analytical Sciences, Vol. 13, No. 3, 1997, pp. 345-349. http://dx.doi.org/10.2116/analsci.13.345

[18] M. Amara and H. Kerdjouj, "Moodified Cation Exchange Resin Applied to Demineralisation of a Liquid Industrial Waste. Comparison to a Classical Treatment and Electrodialysis," Hydrometallurgy, Vol. 65, No. 1, 2002, pp. 5968. http://dx.doi.org/10.1016/S0304-386X(02)00065-8

[19] M. Amara and H. Kerdjouj, "Modification of the Cation Exchange Resin Properties by Impregnation in Polyethyleneimine Solutions: Application to the Separation of Me- tallic Ions," Talanta, Vol. 60, No. 5, 2003, pp. 991-1001. http://dx.doi.org/10.1016/S0039-9140(03)00155-3

[20] M. Amara and H. Kerdjoudj, Journal de la Société Algérienne de Chimie, Vol. 95, 1999, p. 277.

[21] F. Guesmi, Ch. Hannachi and B. Hamrouni, "Selectivity of Anion Exchange Membrane Modified with Polyethyleneimine," Ionics, Vol. 18, No. 7, 2012, pp. 711-717. http://dx.doi.org/10.1007/s11581-011-0627-2

[22] F. Guesmi, Ch. Hannachi and B. Hamrouni, "Modification of the AMX Membrane Surface: Temperature Dependence of Anion Exchange Equilibrium," The Canadian Journal of Chemical Engineering, Vol. 91, No. 8, 2013, pp. 1465-1473. http://dx.doi.org/10.1002/cjce.21744

[23] D. P. Haaland, "Experimental Design in Biotechnology," Marcel Dekker Inc., New York, 1989.

[24] F. Guesmi, C. H. Hannachi and B. Hamrouni, "Effect of Temperature on Ion Exchange Equilibrium between AMX Membrane and Binary Systems of $\mathrm{Cl}^{-}, \mathrm{NO}_{3}^{-}$and $\mathrm{SO}_{4}^{2-}$ Ions," Desalination and Water Treatment, Vol. 23, No. 13, 2010, p. 32. http://dx.doi.org/10.5004/dwt.2010.1837

[25] R. Petrus and J. Warchol, "Ion Exchange between Clinoptilolite and Aqueous Solutions," Microporous Mesoporous Mater, Vol. 61, No. 1-3, 2003, p. 137. http://dx.doi.org/10.1016/S1387-1811(03)00361-5

[26] Ch. Hannachi, M. Ben Sik Ali and B. Hamrouni, "Determination of the Selectivity Coefficient of CMX Cationic Membrane at Various Ionic Strengths," Desalination and Water Treatment, Vol. 10, No. 1-3, 2009, pp. 47-52. http://dx.doi.org/10.5004/dwt.2009.725 